A permanent decline in oil production?

Sir - The analysis underlying Professor Craig Bond Hatfield's prediction of a permanent decline in world oil production within the next 20 years is questionable both factually and conceptually (Nature 387, 121; 1997).

As to the facts, the numbers he gives for present and prospective resources refer only to 'conventional' oil (that is, oil from wells) and ignore other sources such as the Athabasca tar sands and the Orinoco heavy oils. (I understand that Hatfield mentioned them in the original, longer version of his Commentary article.) These alternative sources contain far more oil than can be recovered from wells, but at current crude prices the high cost of extraction has discouraged large-scale production. For the same reason, some conventional oil discoveries have not been developed.

Hatfield's neglect of high-cost oil brings out a conceptual defect of his arithmetic, namely his failure to consider prices. In any mineral, estimates of reserves are meaningful only if they reflect explicit assumptions about prices. When prices change, reserve estimates should be revised. Prices are no less important on the demand side because there is strong evidence of price elasticity in the consumption of energy products. (For a critical survey see D. R. Bohi, Analyzing Demand Behavior: A Study of Energy Elasticities, Johns Hopkins Univ. Press, Baltimore, 1981.)

The experience of the 1980s showed that energy use in manufacturing and transportation can be reduced by switching to less energy-intensive equipment and processes.

My interpretation of Hatfield's projections of conventional oil is that, some time between the years 2000 and 2020, crude prices may have to rise to a level where increasing amounts of oil can be profitably extracted from tar sands and the like. This gradual transition should be well within the power of market forces; futures trading in New York and London enables crude producers, refiners and users to plan several years ahead.

Although the decline in conventional oil output envisaged by Hatfield is indeed possible, total oil output will probably rise for many more decades.

In any case, Hatfield exaggerates the importance of energy in economic growth, which may have been facilitated by low oil prices but is caused primarily by improvements in education, technological change and market-oriented economic policies. These fundamental factors will continue to operate regardless of developments in the oil market.

Hendrik S. Houthakker

Harvard University,

Cambridge, Massachusetts 02138, USA

e-mail:hhouthakker@harvard.edu

Hatfield replies - Hendrik S. Houthakker is certainly correct in his assertion that heavy oil and tar sands are huge potential fuel sources, exceeding the world's economically producible conventional oil by a staggering margin. This is also true of oil shale. Such optimistic generalizations, however, do not convey the difficulties involved in largevolume fuel production from these resources.

Tar sands, heavy oil and oil shale did not help us much during the oil shortages of the 1970s, although research on and attempted development of these resources had begun years earlier. Development of economically feasible sources of energy large enough to compensate for the coming decline in petroleum production requires time, gigantic capital investment and, in some cases, innovative technology.

Time is probably the most severe restriction. That was the message in the last sentence of my Commentary article, in which I stressed that society needs to plan seriously now for the coming decline in the rate of oil production.

I certainly hope that my critics are correct in their view that alternative energy sources will be available to compensate for the decline in conventional oil production, but I fear that they may be too optimistic. During the decline in oil prices in the 1980s, synthetic fuel projects were abandoned as rapidly as they had been initiated during the oil price rises of the 1970s.

Development of substitutes for a significant fraction of our conventional petroleum consumption is a Herculean undertaking that has little chance of success if it can be abandoned in response to shortterm changes in the price of oil. The difficulty is not that potential energy sources do not exist. Rather, it is that they are not likely to be online by the time they are needed (2010-2015), considering the current paucity of development effort.

Houthakker also makes the point that shortage of oil is accompanied by higher oil prices, which cause demand to decrease to approach or match supply, thus alleviating or eliminating the shortage. This is an easy way to solve the problem, in that it simply defines shortages out of existence, although oil prices may become enormous and supply quite small. Such a decline in demand during the oil shortages of the 1970 s did not prevent high inflation and associated economic hardships.

It is better to recognize the impending reality of genuine shortage and to prepare for it now. If we wait for oil shortages to arrive before we react, as we did in the 1960s and 1970s, we shall once again experience greatly accelerated inflation, a serious reduction in economic growth, and strain on the global monetary system.

Craig Bond Hatfield

Department of Geology,

University of Toledo, Toledo, Ohio 43606, USA

\section{Russian science}

\section{misrepresented}

Sir - I am bewildered by Zhores

Medvedev's review of Essays of a Soviet

Scientist by Vitalii I. Gol'danskii (Nature

387, 566-567; 1997).

Most of the review is taken up by a derogatory description of the Academy of Sciences of the USSR and of the privileges granted to its members. Only 13 lines are relevant to the subject of the book review. No wonder Medvedev failed to mention the essays "Struggles of a Soviet scientist", "Why are we lagging behind?", and so on, and in particular the last chapter, which describes the growing anti-semitism in Russia and contains the open letter to President Mikhail Gorbachev on this dangerous trend.

Medvedev asserts that Russian science "has been saved from complete collapse in the past five years only by grants from George Soros and by renting out the buildings of scientific institutes to businesses and foreign companies".

Russian scientists are indeed very grateful for generous financial assistance from Soros (I am myself a Soros Professor), but the donations of the Soros Foundation to Russian scientists (US\$65 million since 1994) total only just over half as much as the grants from the Russian Foundation for Basic Research (\$122 million).

Meanwhile, the Russian Academy of Sciences received from the federal budget in 1996 (for one year) about $\$ 350$ million, far less than is needed.

Eugen F. Makarov

Institute of Chemical Physics

of the Russian Academy of Sciences,

Kosygin Street 4,

Moscow 117334,

Russia 